\title{
Vocalização da lateral palatal em comunidades arapiraquenses
}

\author{
Ronaldo Gomes dos Santos (Graduando em letras/ UNEAL) ${ }^{1}$ \\ Brunna de Oliveira Tenório (Graduanda em letras/ UNEAL) ${ }^{2}$ \\ Jeylla Salomé Barbosa dos Santos (Doutora em Letras e Linguística UFAL/ UNEAL) ${ }^{3}$
}

\begin{abstract}
Resumo - Neste trabalho apresentaremos um fenômeno linguístico nomeada vocalização da lateral palatal, abordando como esta variação ocorre nos seguintes fatores sociais: sexo, idade e escolaridade, baseado em falantes de Arapiraca-AL, usando os áudios do banco de dados alagoano da Universidade Federal de Alagoas-UFAL, fundamentado nossa pesquisa em Labov, Tarallo, Mussalim e Bagno. Diante dessa análise foi possível perceber que o apagamento do som consonantal por um vocálico nesses casos não tem relação com escolaridade ou de sexo que se polícia mais que o outro ao pronunciar as palavras que ocorre essa variação. Nosso objetivo assim como o da sociolinguística é corrigir o dito "errado" pela gramática normativa, e estudar os motivos dessa variação. Pensando o porquê desse fenômeno ser comum em sociedades desfavorecida, porém pensando esse fenômeno sem preconceito já que pensamos em um lugar de fala onde a língua é livre, pois não falamos o que escrevemos, já que a emissão do som vocálico é mais fácil, por isso faz-se menos esforço para pronunciar palavras. O falante descarta as dificuldades na articulação do som, causando assim essa variação. Mas o português não-padrão é logico, bem estruturado e segue as tendências naturais da língua. Nesse caso o preconceito linguístico é desnecessário e irrelevante. Mostrando que a linguagem é um sistema de signos socializados, ou seja, seus elementos só adquirem significado quando inseridos em contextos de inter-relação, pois cada signo por si só não possui significado relevante. Quando se estuda e compreende esses conceitos, nosso ouvido fica mais sensível a língua falada, respeitando suas variações e seus falantes.
\end{abstract}

Palavras-chave: Vocalização. Sociolinguística. Variação.
Abstract - In this paper we will present a linguistic phenomenon called vocalization of the palatal lateral, addressing how this variation occurs in the following social factors: sex, age and education, based on speakers from Arapiraca-AL, using the audios from the Alagoas- Federal University of Alagoas- UFAL, based our research on Labov, Tarallo, Mussalim and Bagno. In view of this analysis, it was possible to notice that the erasure of the consonant

\footnotetext{
${ }^{1}$ Aluno do curso de Licenciatura em Português, UNEAL - Campus IV e integrante do NEL - Núcleo de Estudos Literários, e do grupo de pesquisa GELIC, ronaldogomer123@gmail.com:

${ }^{2}$ Aluna do curso de Licenciatura em Inglês, UNEAL - Campus IV, brunnaoli98@ hotmail.com:

${ }^{3}$ Professora do campus IV, doutoranda em Letras e Linguística UFAL/UNEAL, jeylla@hotmail.com:
} 
sound by a vowel in these cases is not related to education or sex, which is more police than the other when pronouncing the words that this variation occurs. Our objective, as well as that of sociolinguistics, is to correct the so-called "wrong" by normative grammar, and to study the reasons for this variation. Thinking why this phenomenon is common in disadvantaged societies, but thinking about this phenomenon without prejudice since we think of a place of speech where the language is free, because we do not speak what we write, since the emission of the vowel sound is easier, for it takes less effort to pronounce words. The speaker discards difficulties in articulating the sound, thus causing this variation. But non-standard Portuguese is logical, well-structured and follows the natural tendencies of the language. In this case, linguistic prejudice is unnecessary and irrelevant. Showing that language is a system of socialized signs, that is, its elements only acquire meaning when inserted in contexts of interrelation, since each sign by itself has no relevant meaning. When we study and understand these concepts, our ears become more sensitive to the spoken language, respecting its variations and its speakers.

Keywords: Vocalization. Sociolinguistics. Variation.

\section{Introdução}

Vocalização é o fenômeno fonético que consiste na transformação de um som consonantal por um som vocálico, neste caso a transformação do LH em I. A consoante lateral palatal é representada no alfabeto fonético internacional pelo símbolo $[K]$ e na língua portuguesa pelas letras "LH", este fonema é oral e sonoro produzida com a ponta da língua tocando o palato. A semivogal anterior fechada e arredondada é representada pelo símbolo [y] no alfabeto fonético internacional, a letra “i”. Seu ponto de articulação é próximo onde é produzida a consoante lateral palatal. A emissão do som vocálico é mais fácil, por isso faz-se menos esforço para pronunciar palavras como: trabalho, velho, mulher, olha etc. O falante descarta as dificuldades na articulação do som, causando assim essa variação. Tarallo (1986, p. 8) afirma que "variantes linguísticas são, portanto, diversas maneiras de dizer a mesma coisa em mesmo contexto e com o mesmo valor de verdade", assim podemos perceber que a sociolinguística parte do pressuposto que se há entendimento entre os falantes então há uma 
conversação. É interessante ressaltar a gíria, que é uma linguagem de caráter popular, pois existe a gíria "óia" que significa olhar ou observar e "véi” que é um pronome de tratamento, é nítida a ocorrência do fenômeno de vocalização da lateral palatal e como a língua se comporta na sociedade para gerar novos vocábulos com o mesmo valor de verdade. Segundo Marcos Bagno (1997) é ideal que os educadores expliquem aos alunos que o português-padrão e nãopadrão são diferentes, mas o português não-padrão é lógico, bem estruturado e segue as tendências naturais da língua, ou seja há uma explicação coerente para a ocorrência de determinado fenômeno, seja ele social e/ou fonético.

\section{Sociolinguística}

Estudar sociolinguística vai muito além de saber conceitos, após se deparar com este estudo o ouvido fica mais sensível à língua falada, pois é exatamente isso que a sociolinguística deve fazer: "demonstrar a covariação sistemática das variações linguística e social. Ou seja, relacionar as variações linguísticas observáveis em uma comunidade às diferenciações existentes na estrutura social desta mesma sociedade" (BRIGHT apud ALKMIM, 2005, p. 28), portanto o objetivo da sociolinguística não é corrigir o dito "errado" pela gramática normativa e sim estudar os motivos de uma determinada variação. De acordo com Alkmim (2001, p. 28), “a sociolinguística é uma área que existe, dentro da linguística, para tratar, especificamente, das relações entre linguagem e sociedade.”, a sociolinguística é, conceituando basicamente, o estudo da língua falada que aborda fatores do contexto social como: identidade social do falante e do ouvinte (sexo, idade, escolaridade, classe etc) e atitudes linguísticas, como o preconceito.

Alkmim (2001, p.31) diz que “o objeto da sociolinguística é o estudo da língua falada, observada, descrita e analisada no contexto social, isto é, em situações reais de uso.”, partindo deste fato é perceptível que a comunicação é uma área muito interessante de ser estudada, e tão necessária quanto estudar gramática, estudar a língua falada desconstrói muitos conceitos antes pré-determinados, pois analisar quais os fatores que levam uma pessoa a realizar determinada variação nos faz entender o porquê dessa ocorrência. Como os tempos e as gerações mudam a língua também se altera seguindo o curso de sua comunidade, por 
exemplo, estudar o fator idade na variação da palavra "calçada", é percebível que uma pessoa mais velha pode vir de uma educação diferente em um tempo diferente do que um jovem com a educação atual com a modernidade. Então este e outros fatores sociais irão levar a uma conclusão final explicativa, por meio de muita investigação, da razão desta ocorrência em pessoas de idades diferentes.

Geralmente inicia-se uma pesquisa escolhendo uma comunidade de fala, para Labov (1972, p. 120-121):

a comunidade de fala não é definida por nenhum acordo/contrato no uso de elementos de língua, mas pela participação em um jogo de normas compartilhadas; tais normas podem ser observadas em tipos claros de comportamentos avaliativos e pela uniformidade de modelos abstratos dos padrões da variação que são invariáveis em relação aos níveis particulares de uso.

Ou seja, a comunidade de fala é composta por variadas pessoas que usam da mesma língua e mesma regras de português não-padrão, pois não falamos como escrevemos, entretanto, cada um à sua maneira. Após escolher a comunidade, há a definição do fenômeno ou variação, seleciona os fatores sociais a serem analisados e comparados ou a atitude linguística então é só aplicar a metodologia ideal para o tipo de pesquisa.

A sociedade é o campo linguístico onde tudo acontece, e quando falamos de fenômenos, deixar de citar a variação no modo como os indivíduos falam determinadas palavras é deixar subentendido que só existe um caminho para expressar algo. É mostrar que se pronunciarmos determinada palavra de uma forma diferente da padrão, estamos cometendo um erro incompreensível. Porém, sabemos que há sim possibilidade de entendimento, e um fator primordial para que isso aconteça é o contexto em que a palavra está inserida.

Tratando-se do fenômeno que estamos discorrendo sobre, "vocalização da lateral palatal", usaremos o seguinte exemplo: Uma pessoa fala a palavra "Caia", a princípio acharemos que se trata de uma flexão do verbo "Cair", entretanto, se a pessoa diz "Tem muita sujeira na caia", logicamente saberemos que o que ele quer dizer está referindo-se ao estado em que se encontra a calha. O linguista francês, Émile Benveniste (1902 - 1976) dizia que a linguagem é um sistema de signos socializado, ou seja, seus elementos só adquirem 
significado quando inseridos em contextos de inter-relação, pois cada signo por si só não possui significado relevante.

\section{Metodologia}

Por estudar sociolinguística, o objetivo deste trabalho é analisar os fatores sociais: sexo, idade e escolaridade na comunidade linguística de Arapiraca - AL no fenômeno de vocalização da lateral palatal, para chegar à conclusão de quem faz mais esta variação se é homem ou mulher, jovem ou idoso, com alta ou baixa escolaridade e as possíveis razões para esta variação ocorrer em determinado fator social. Usaremos os áudios da comunidade de Arapiraca - AL do banco de dados alagoano da Universidade Federal de Alagoas para análise.

Para identificarmos os áudios e analisa-los de maneira que não houvesse equívocos, separamos os mesmos por códigos, e esses podem ser lidos como na tabela abaixo:

\begin{tabular}{|l|llll|}
\hline AR18M06 & $\begin{array}{l}\text { Cidade: Arapiraca; Idade: } 18 \text { anos; Sexo: } \\
\text { Escolaridade: } 6^{\text {a }} \text { série }\left(7^{\circ} \text { ano }\right)\end{array}$ & & & \\
\hline AR30F15 & $\begin{array}{l}\text { Cidade: Arapiraca; Idade: } 30 \text { anos; } \\
\text { Escolaridade: Ensino superior completo. }\end{array}$ & Feminino; \\
\hline AR40M15 & $\begin{array}{l}\text { Cidade: Arapiraca; Idade: } 40 \text { anos; } \\
\text { Escolaridade: Ensino superior completo. }\end{array}$ & Masculino; \\
\hline AR68F01 & $\begin{array}{l}\text { Cidade: Arapiraca; Idade: } 68 \text { anos; } \\
\left.\text { Escolaridade: } 1^{\text {a }} \text { série (fundamental } 1\right) .\end{array}$ & Feminino; \\
\end{tabular}

Embora tendo utilizado os áudios já gravados do banco de dados online e não ter saído às ruas para coletá-los, analisá-los não foi uma tarefa tão simples quanto parece. Foi preciso dividir os áudios em três grupos que ficaram da seguinte forma:

$1^{\circ}$ Grupo: (ARA 1)

- 8 áudios: 4 de pessoas do sexo masculino e 4 do sexo feminino;

- Faixa etária: Dos 18 aos 30 anos; 
- Escolaridade: Do fundamental (1 e 2) ao superior.

$2^{\circ}$ Grupo: (ARA 2)

- 8 áudios: 4 de pessoas do sexo masculino e 4 do sexo feminino;

- Faixa etária: Dos 40 aos 60 anos;

- Escolaridade: Do fundamental (1 e 2) ao superior.

$3^{\circ}$ Grupo: (ARA 3)

- 8 áudios: 4 de pessoas do sexo masculino e 4 do sexo feminino;

- Faixa etária: Dos 67 aos 89 anos;

- Escolaridade: Do fundamental (1 e 2) ao superior.

\section{Variação de $[\boldsymbol{\Lambda}] / \mathrm{lh} /$}

Depois de analisar os dados, percebemos que o apagamento do $/ \mathrm{lh} /$, representado por [j] e que nos dados aparece como 0, acontece 240 vezes. Sendo realizado 120 vezes por pessoas do sexo masculino e 120 do feminino. Das quais, 69 feitas por adultos, 104 por idosos e 67 por jovens. Entre as 240, o fenômeno aconteceu 114 vezes com pessoas que participaram do ensino fundamental, mesmo que não tenham concluído, e $126 \mathrm{com}$ pessoas que participaram do ensino superior. Para facilitar a distinção entre os grupos, criamos os seguintes gráficos:

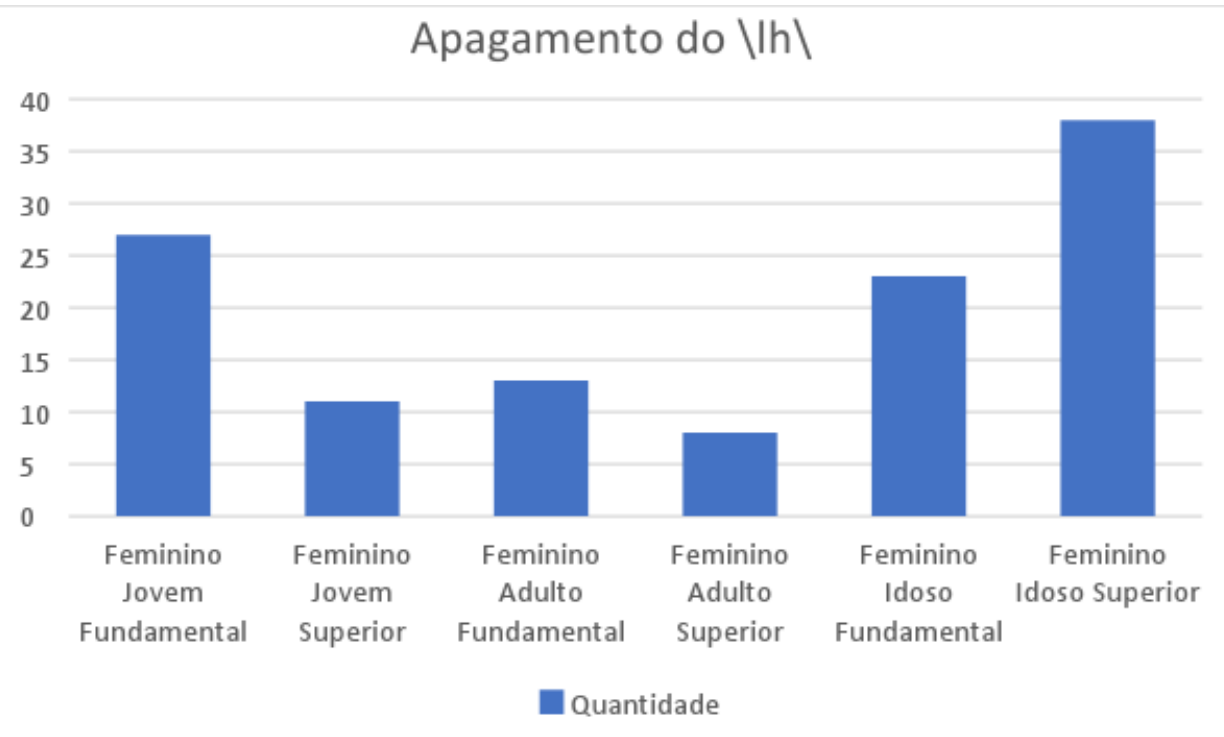




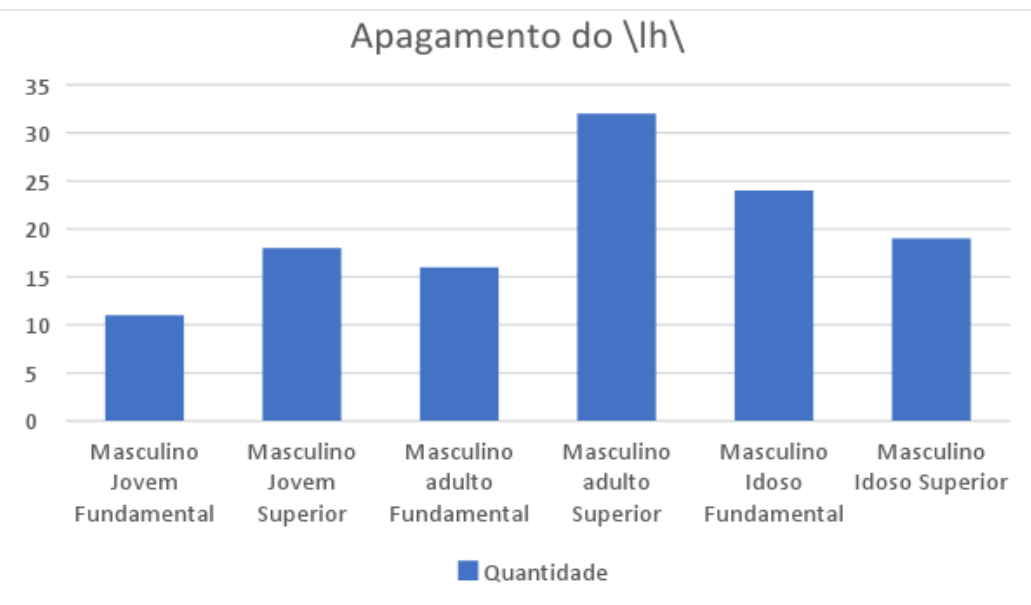

Em contrapartida, a reprodução do $/ \mathrm{lh} /$, representado foneticamente por $[K]$ e que nos dados aparece como 1, é realizado 80 vezes. Sendo 53 vezes por pessoas do sexo masculino e 27 do sexo feminino. Sendo 33 vezes entre os adultos, 43 entre os idosos e 4 entre os jovens. Com 61 realizações entre pessoas que participaram do ensino fundamental e 19 vezes por pessoas do ensino superior. Veja uma descrição mais detalhada nos gráficos abaixo:

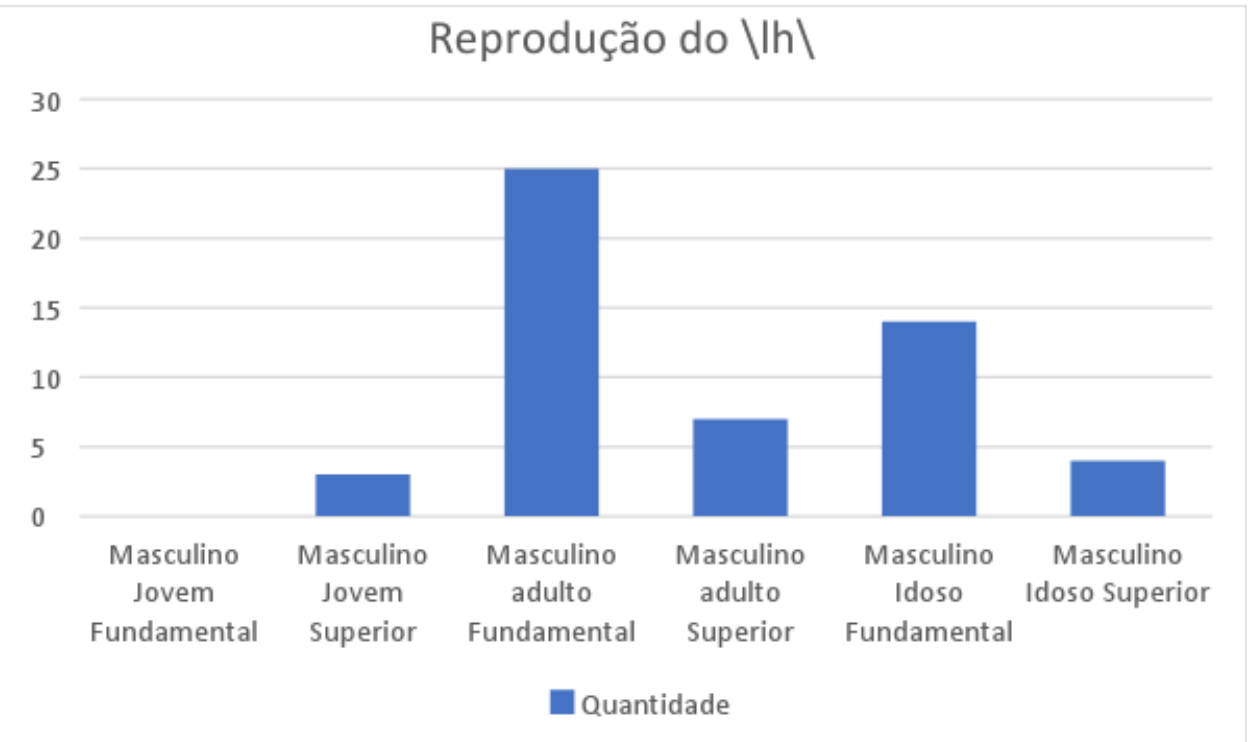




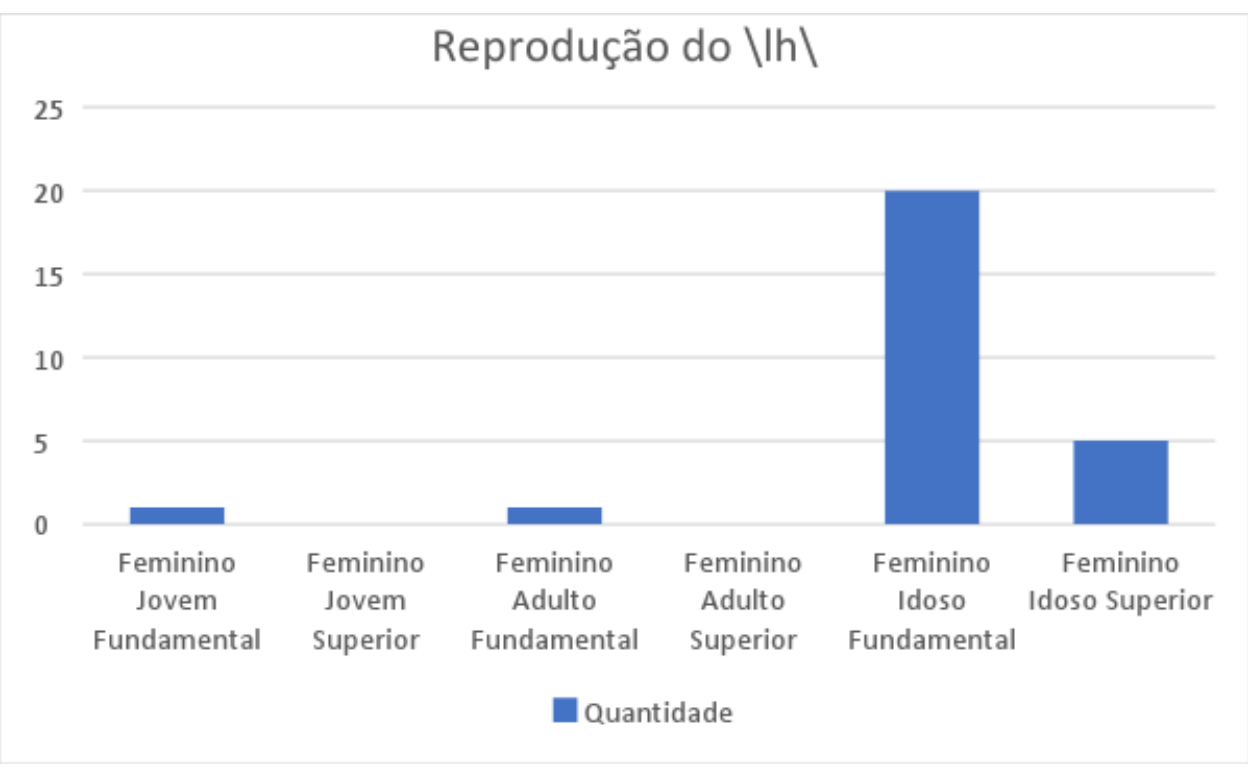

De acordo com as informações anteriormente descritas, concluímos que os idosos fazem mais o apagamento do LH e os jovens fazem menos. Entre os idosos, esse apagamento acontece 43 vezes com os que são do sexo masculino e 61 vezes com os do sexo feminino, e, esse fenômeno ocorre com mais frequência entre os que estão enquadrados na questão ensino superior. Concluímos também que, os jovens que menos fazem o apagamento são os que se enquadram no quesito ensino superior. Tendo 29 realizações com o sexo masculino e 38 com o sexo feminino.

No geral, os dados mostram que considerando o grau de escolaridade, é entre as pessoas do ensino superior que o apagamento mais acontece. E que analisando o quesito sexo, temos um empate, pois tanto homens como mulheres fazem os mesmos números de apagamentos. Por fim, como já citado anteriormente, os idosos são os que mais fazem o apagamento $\mathrm{e}$ os jovens os que menos fazem. 


\section{Conclusão}

Percebe-se assim que os idosos fazem mais o apagamento do LH. Porém, eles também são os que mais reproduzem o LH.

Considerando o grau de escolaridade, as pessoas do ensino superior que o apagamento mais acontece. E que os que mais reproduzem o LH são pessoas do ensino fundamental.

Analisando o quesito sexo, temos um empate, tanto homens como mulheres fazem os mesmos números de apagamentos. Já no que se refere a aplicação do LH, os homens fazem mais.

Não é descaso com a língua, mas um condicionamento do vicio de fala, dependendo da comunidade que o falante se adeque pode ocorrer com maturidade. Por esse fato o uso da vogal no ligar do encontro consonantal é tão ocorrente, ou seja, uma forma de facilitar a comunicação entre os falante de determinada comunidade, e ate mesmo uma forma de manter viva e preservar a identidade linguística da comunidade, e não apenas pelo fato da pronuncia ser mais fácil ou mais simples de se pronunciar. 


\section{Referências}

BAGNO, Marcos. A língua de Eulália: novela sociolinguística, São Paulo: Contexto, 1997.

LABOV, William. Padrões sociolinguísticos. São Paulo: Parábola Editorial, 2008.

MUSSALIN, F; BENTES A. C. (orgs.). Introdução à Lingüistica: Domínios e Fronteiras.

Vol. 1. São Paulo: Cortez Editora, 2001.

TARAllo, Fernando (1986). A Pesquisa Sociolinguística. São Paulo: Ática. 